\title{
Struktur Histologis Hepar, Intestinum, dan Ren Burung Cerek Jawa (Charadrius javanicus Chasen 1938) Dengan Kontaminasi DDT di Delta Sungai Progo Yogyakarta
}

\author{
DEWI PUSPITA SARI ${ }^{1}$, SUWARNO HADISUSANTO ${ }^{2}$, ISTRIYATI ${ }^{2}$ \\ ${ }^{1}$ Program Studi Pendidikan Biologi FKIP, Universitas Sebelas Maret Surakarta \\ Jl. Ir. Sutami 36 A Kentingan Surakarta Jawa Tengah \\ email: dewibioedu@gmail.com \\ ${ }^{2}$ Pascasarjana Fakultas Biologi, Universitas Gadjah Mada \\ Jl. Teknika Selatan Sekip Utara Sleman Yogyakarta 55281 \\ email: suwarno_hsusanto@yahoo.co.id
}

\begin{abstract}
Residues of DDT (Dichloro Diphenyl Trichloroethane) in the river environment can get into the Bird's body through an intermediary Javan Plover natural feed. Residues of DDT will experience biomagnification and biotransformation in the body organism. The purpose of this research was to determine residue of DDT in the Progo's mudflat region, several organs of birds, and their impact on liver, intestine, and kidney Javan Plover. This research was located in Progo's downstream. The method of environment and feed sampling done directly on site. The bird sampling using mist nets. Detection of residues DDT in environment samples by gas chromatography. Measurement of DDT residues in feed and organs of birds with spectrophotometer. Preparation of histological slide from liver, intestine, and kidney using paraffin method (with Hematoxilin \& Eosin and Mallory Acid Fuchsin staining). Quantitative Data obtained from the measurement results of environment, feed, and organs of Javan Plover samples. Qualitative data analize by descriptively. The analysis showed DDT residues detected in area's Progo downstream, natural feed and Javan plover's organ. Analysis shows chronic effects posed by DDT residue on the histological structure of liver, intestine, and kidney of Javan Plover.
\end{abstract}

Keywords: DDT (Dichloro Diphenyl trichloroethane), histological structure, Javan Plover (Charadrius Javanicus Chasen 1938), Progo's River

\section{PENDAHULUAN}

Insektisida DDT dimanfaatkan untuk memusnahkan serangga yang merusak tumbuhan dan penyebab penyakit malaria. Karakter DDT adalah persisten (Persisten Organic Pollutans) di lingkungan, dapat dipindahkan oleh angin dengan jarak jauh, kelarutan dalam lemak tinggi (lipofilik), bioakumulatif, dan biomagnifikatif (Walker et al., 2001). Dalam jangka waktu 40 tahun, residu DDT masih ditemukan di lingkungan serta terdistribusi secara global dari sumber polusi menuju wilayah lain (Sudaryanto et al., 2005).

Delta Sungai Progo merupakan daerah hilir dari sungai yang berhulu di kawasan perkebunan di Gunung Sindoro dan melewati daerah Yogyakarta yang banyak memiliki lahan pertanian. Burung Cerek Jawa (Charadrius javanicus Chasen 1938) adalah salah satu satwa liar non target yang terbiasa mencari makan di daerah delta Sungai Progo. Insektisida DDT masuk ke tubuh burung dengan perantara lingkungan maupun rantai makanan. Invertebrata kelompok Crustacea dan Oligochaeta sebagai potensi pakan Cerek Jawa dapat terkontaminasi DDT dengan level yang lebih tinggi dibanding konsentrasi di lingkungan (Nelson \& Gish, 1980). Insektisida DDT dapat berpengaruh pada struktur histologis organ dalam Burung Cerek Jawa. Insektisida DDT bersifat hepatotoksik (Stine \& Brown, 1996), memicu pembesaran hepar, menginduksi enzim sitokrom P450, nekrosis sentrolobuler (Lu, 2006), perlemakan hati dan memunculkan fibrosis hepar (Jeyaratnam \& Koh, 2009). Hasil metabolit DDT memiliki kemampuan untuk melintasi sel epitel pada intestinum kemudian masuk ke aliran darah 
secara difusi dan mampu menyebabkan kerusakan pada tubulus renalis (Stine \& Brown, 1996). Tujuan dari penelitian ini adalah untuk mengetahui konsentrasi residu DDT di organ hepar, intestinum, ren dari Burung Cerek Jawa beserta struktur histologisnya.

\section{METODE}

Lapangan. Penangkapan Burung Cerek Jawa menggunakan jaring kabut. Jaring dipasang dengan bentangan berukuran lebar 1 meter dan panjang 100 meter. Jaring terbuat dari bahan nilon dan setiap 2 meter dipasang penyangga (Withworth et al., 2008). Jaring dipasang ketika sore hari (16.30-19.00), malam hari (pukul 21.00-24.00), dan dini hari (pukul 03.00-06.00). Setelah memasang, jaring harus tetap dijaga supaya burung yang tertangkap tidak sampai mati terjerat (dilakukan pengecekkan tiap 30 menit sekali).

Laboratorium. Untuk mengetahui kadar DDT Invertebrata dan Burung Cerek Jawa dengan menggunakan spektrofotometer. Apabila sampel berupa cairan maka langsung dapat diproses, namun jika berupa padatan maka harus dihancurkan dan dihomogenkan supaya dapat larut. Sebagai contoh sampel cair yang berupa darah ditambahkan $0,1 \mathrm{mg}$ EDTA, dan selanjutnya sampel darah disimpan pada suhu $-20{ }^{0}$ C. Sampel padat sebagai contoh adalah hepar didapat dengan cara pembedahan kemudian hepar dihancurkan dan ditambahkan 0,1 mg EDTA, dan selanjutnya sampel disimpan pada suhu $-20{ }^{0} \mathrm{C}$ sampai dianalisis kandungan DDT (Munajim,1990). Pembuatan preparat histologis dari hepar, intestinum, dan ren dilakukan melalui beberapa tahapan dengan pewarnaan Hematoxilin \& Eosin dan Mallory Acid Fuchsin. Cara pembuatan sediaan dimodifikasi dari McManus \& Mowry (1960). Pengamatan preparat histologis dilakukan dengan menggunakan mikroskop cahaya sebanyak 2 ulangan tiap slide dengan masingmasing 5 bidang pandang pengamatan.

Analisis Data. Data yang dikumpulkan berupa data kuantitatif dan kualitatif. Data kuantitatif berupa hasil pengukuran DDT dengan Kromatografi gas dan spektrofotometer. Data Kualitatif berupa analisis residu DDT di organ burung. Pengamatan dengan pewarnaan Mallory Acid Fuchsin dan Hematoxilin \& Eosin. Pewarnaan Mallory Acid Fuchsin dan Hematoxilin \& Eosin digunakan untuk mengetahui struktur histologis beserta perubahannya. Pengamatan struktur histologis menggunakan mikroskop listrik dan pengambilan gambar dengan mikroskop listrik berkamera.

\section{HASIL}

\section{Residu DDT pada Cerek Jawa}

Tabel 1. Hasil Analisis Residu DDT di dalam Hepar, Intestinum, dan Ren Burung Cerek Jawa (dalam ppm)

\begin{tabular}{cccc}
\hline Sampel & Hepar & Ren & Intestinum \\
\hline 1 & 0,72 & 0,31 & 0,62 \\
2 & 0,38 & 0,33 & 0,82 \\
3 & 0,44 & 0,83 & 0,76 \\
4 & 0,30 & 0,41 & 0,62 \\
5 & 0,48 & 0,36 & 0,72 \\
\hline
\end{tabular}
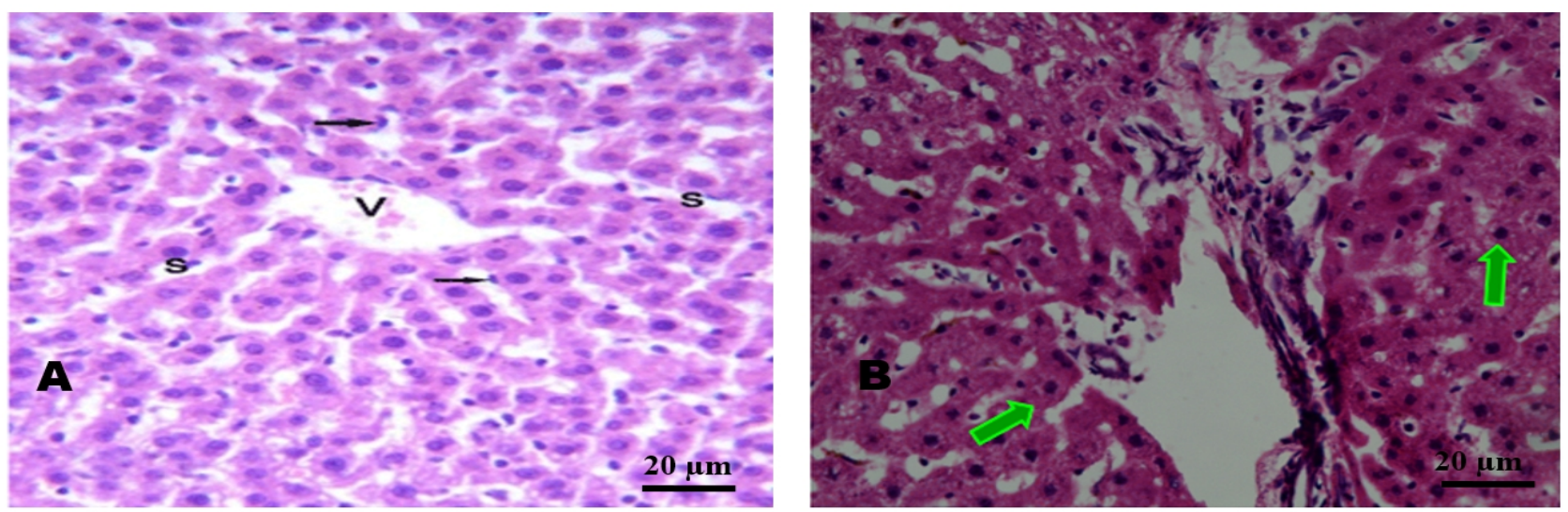

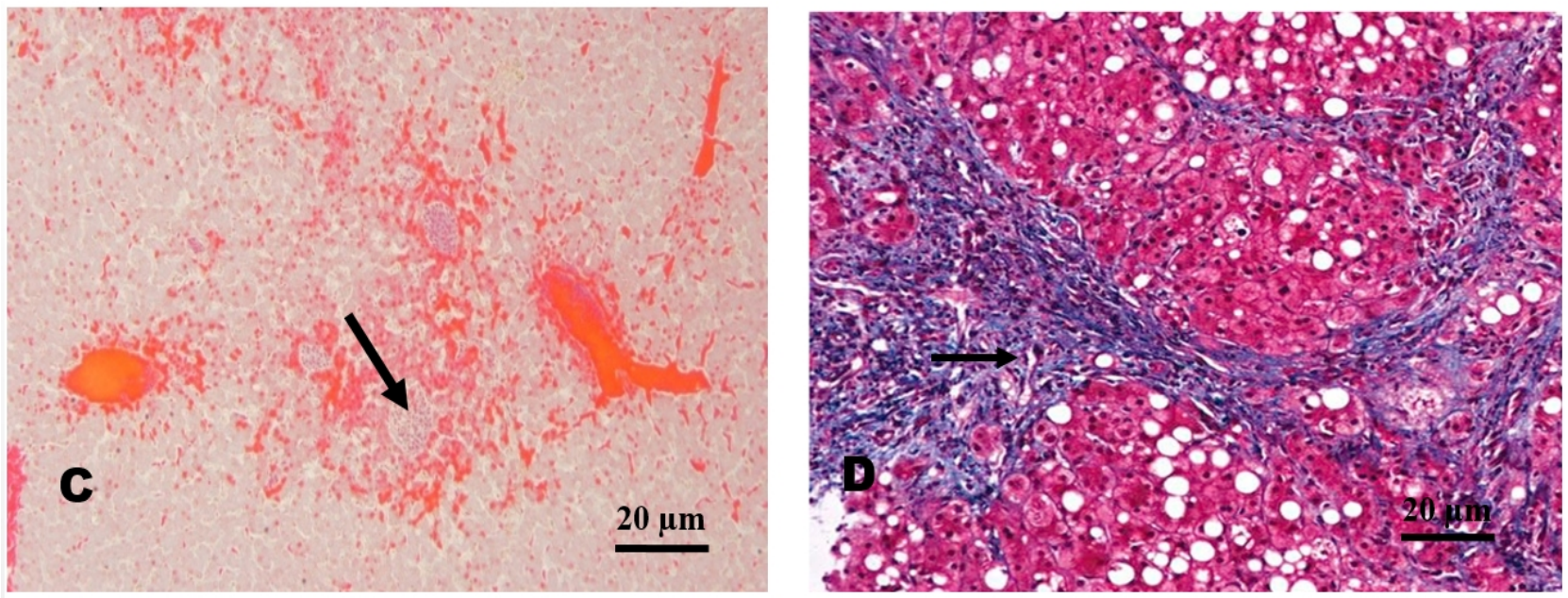

Gambar 1. Fotomikrograf hepar Cerek Jawa (Charadrius javanicus) dengan residu DDT sebesar 0,30 ppm (A), 0,48 ppm (B), 0,44 ppm, 0,72 ppm, perbesaran objek 400x, pewarnaan Hematoxilin \& Eosin (A,B) dan Mallory Acid Fuchsin (C,D). Keterangan. V: Vena sentralis, S: Sinusoid
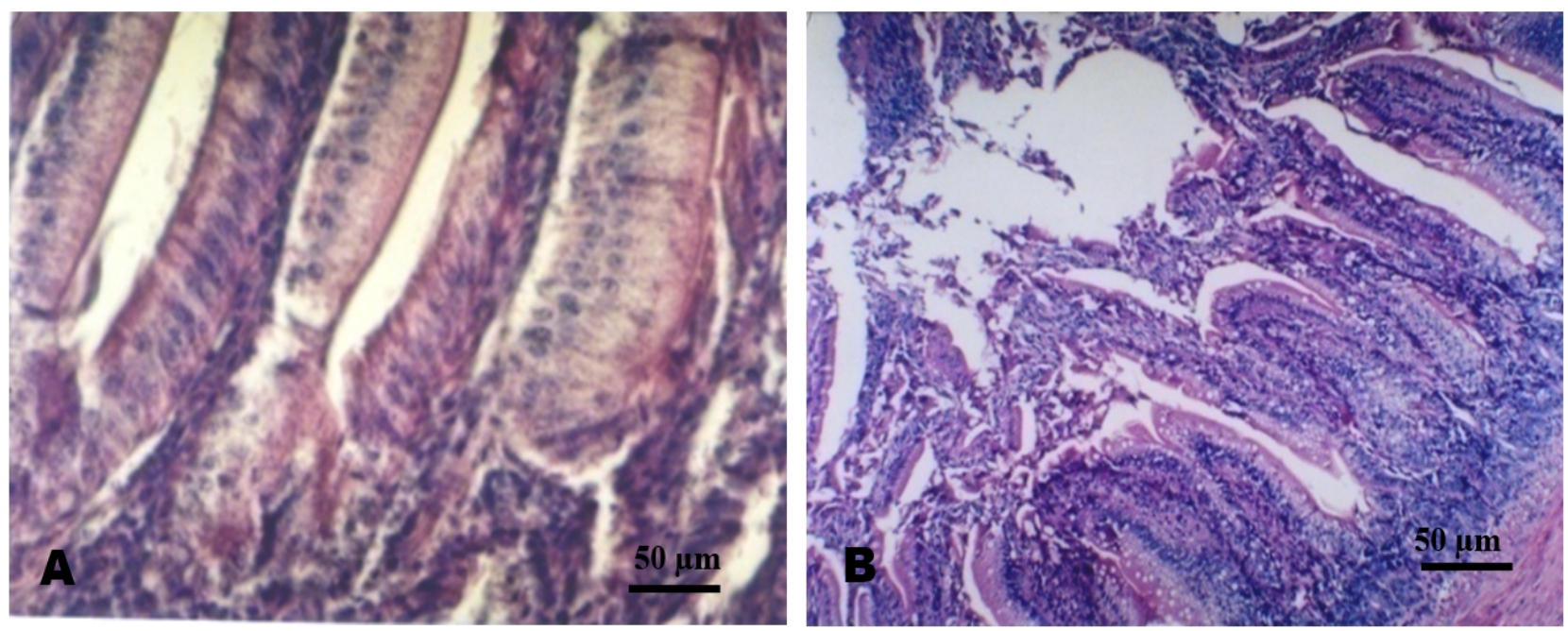

Gambar 2. Fotomikrograf Intestinum Cerek Jawa (Charadrius javanicus) dengan residu DDT sebesar 0,62 ppm (A), 0,82 ppm (B), perbesaran objek 400x, pewarnaan Hematoxilin \& Eosin
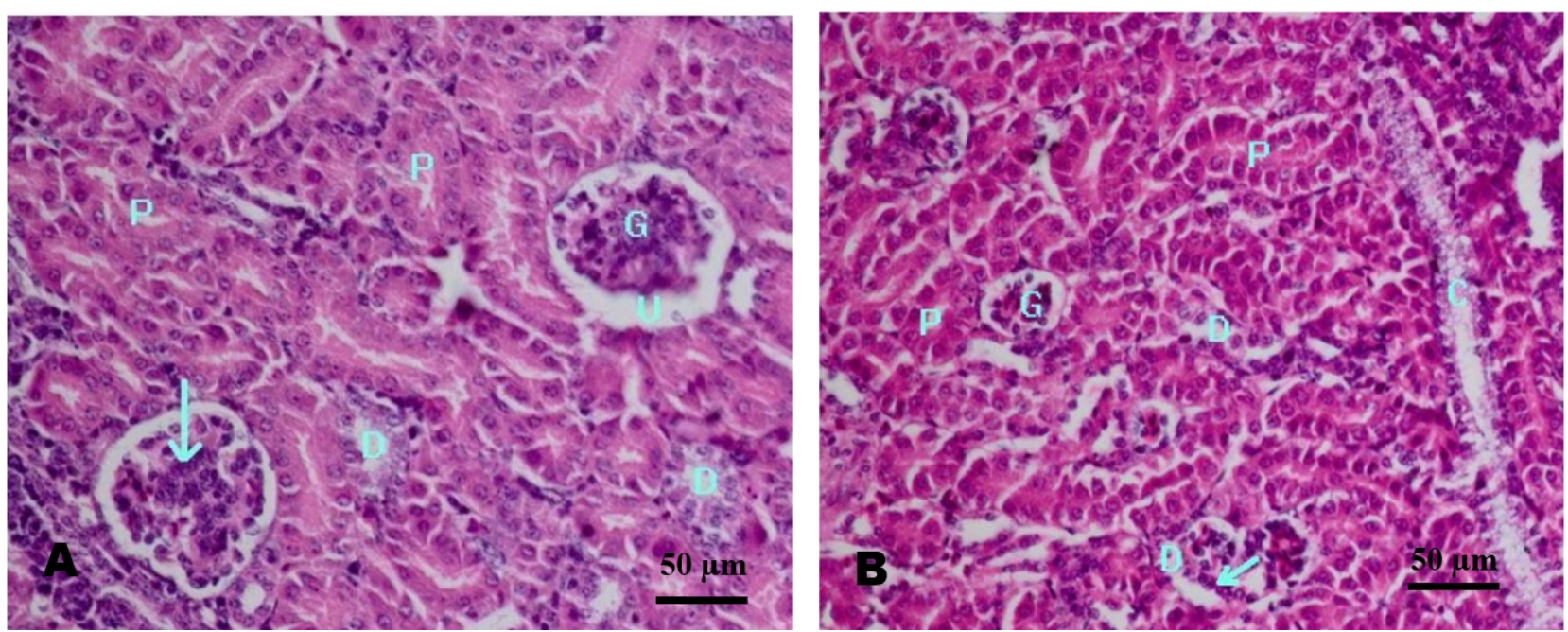


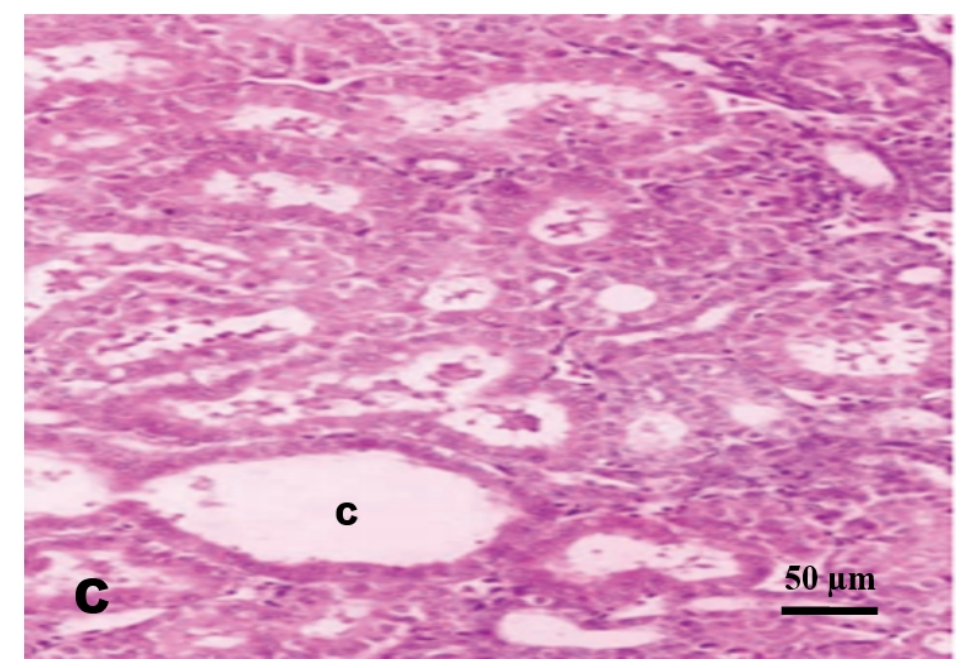

Gambar 3. Fotomikrograf Ren Cerek Jawa (Charadrius javanicus) dengan residu DDT sebesar 0,31 ppm (A), 0,41 ppm (B), dan 0, 83 ppm, perbesaran objek 400x, pewarnaan Hematoxilin \& Eosin. Keterangan: P: Tubulus Kontortus Proksimal, D: Tubulus Kontortus Distal, C: Tubulus Colectivus, G: Glomerolus. Tanda panah (A) sel Mesengial, (B) makula densa

\section{PEMBAHASAN}

Hasil pada tabel 1 menunjukkan perbedaan konsentrasi residu DDT yang sangat beragam. Sampel Cerek Jawa ke 2 dan 5 menunjukkan kondisi yang hampir sama, residu DDT tertinggi dijumpai pada Intestinum. Intestinum memiliki nilai residu tertinggi karena intestinum merupakan organ yang pertama kali melakukan kontak dengan DDT. Pajanan toksikan di saluran cerna dapat terjadi bersama masuknya pakan. Menurut Hayes \& Laws (1991), kontaminasi DDT melalui kapiler di lamina propia intestinum dapat meningkatkan kandungan DDT dalam darah yang akhirnya akan menyebar ke seluruh tubuh. Pada sampel Cerek jawa ke 1 menunjukkan kondisi yang berbeda dengan sampel sebelumnya. Residu DDT dalam hepar kemungkinan berasal dari kilomikron yang dikeluarkan oleh sistem sirkulasi (Guyton \& Hall, 1997). Pada sampel Cerek Jawa 3 menunjukkan kondisi yang berbeda. Residu tertinggi dijumpai pada Ren. Kondisi ini mungkin terjadi karena proses biotransformasi yang berjalan lambat pada organ sebelumnya. Senyawa-senyawa lipofil seperti DDT setelah terfiltrasi glumerular akan direabsorpsi melalui tubuli ginjal menuju sistem peredaran darah (Stine \& Brown, 1996).

Hasil Pengamatan Struktur Histologis Hepar. Residu tertinggi pada sampel Cerek Jawa 1 menunjukkan struktur yang mulai mengalami perubahan dari struktur normal sebuah hepar (Gambar 1). Sampel Cerek Jawa ke 2 dan 4 dengan nilai menunjukkan kondisi struktur histologis yang normal. Sampel Cerek Jawa ke 3 dan 5 menujukkan adanya perubahan struktur histologis. Gambar A, menunjukkan kondisi hepar yang normal. Hepatosit tersusun dalam lobulus hepar, inti dengan batas jelas dan terletak setralis. Vena sentralis di tengah dan sinosoid tersebar difus, tidak ditemui adanya pelebaran serta tak mengandung bentukan vakuola. Tidak dijumpai degenerasi sel lemak sentro-perilobuler. Kondisi histologis yang masih normal menunjukkan masih berfungsinya enzim sitokrom P450. Sitokrom P450 yang merupakan enzim yang dapat mengoksidasi paling banyak bahan kimia yang masuk dan ditemukan dalam jumlah besar di centrilobular area (Stine \& Brown, 1996). Gambar B menunjukan gejala kerusakan hepar. Tanda panah menunjukkan gejala degenerasi hidrofobik. Jika toksin belum dapat dinetralisir, maka infulk air semakin besar sehingga sebagian organel sel seperti retikulum endoplasma dapat berubah menjadi kantongkantong berisi air. Perubahan seperti ini disebut perubahan hidrofik. (Price \& Anderson, 1991). Gambar C, menunjukkan gejala mengarah pada Infiltrasi sel radang (ditunjukkan oleh tanda panah) limfosit pada vena sentralis disebabkan rusaknya sel endotel yang sangat peka terhadap 
zat racun. Menurut Ressang (1984) peradangan pada hepar dimulai pada vena sentralis sebagai tempat penampungan darah yang berasal dari arteri hepatica dan vena porta. Tanda panah pada gambar D menunjukan area periportal mulai muncul gejala fibrosis. Munculnya jaringan ikat dalam kondisi terpapar DDT menunjukkan adanya gangguan yang mengarah ke fibrosis. Jika kondisi yang terjadi secara terus menerus maka jaringan ikat akan membesar dan pada akhirnya memunculkan kondisi yang lebih parah yaitu sirosis hepar. Biotransformasi DDT menjadi metabolit DDA, menghasilkan senyawa samping etanol. Penambahan Etanol dalam jangka panjang mampu memicu munculnya sirosis hepar (Made \& Niruri, 2006).

Hasil Pengamatan Struktur Histologis

Intestinum. Kemampuan enzim dalam intestinum untuk memetabolisme senyawa DDT menjadi senyawa yang tidak begitu beracun menyebabkan kondisi seluruh preparat histologis intestinum residu DDT dengan kisaran nilai 0,62 ppm- 0,82 ppm menjadi normal (Gambar 2). Kondisi normal pada semua pengamatan menunjukkan kemampuan individu yang baik terhadap perubahan lingkungan.

Hasil pengamatan pada Gambar 2 menunjukkan tidak ada perubahan pada struktur histologis Intestinum. Villi masih mempunyai struktur yang utuh. Dinding intestinum dengan bantuan enzim-enzim katalisis mempunyai kemampuan untuk melakukan metabolisme (reaksi biokimia) bagi senyawa tertentu sebelum mencapai pembuluh darah vena hepatika (Kuehnel, 2003). Struktur intestinum yang normal juga dimungkinkan karena intestinum bukan merupakan target toksik dari DDT. Insektisida DDT umumnya bersifat neurotoksik, hepatotoksik dan genetoksik (Stine \& Brown, 1996).

Hasil Pengamatan Struktur Histologis Ren. Gambar A, menunjukkan kondisi ren dalam keadaan normal. Mayoritas nefron tanpa lengkung Henle dan terbatas dalam jumlah sepenuhnya menuju korteks (Gambar 3). Korpuskula renalis terdiri dari Kapsul Bowman bagian luar yang dipisahkan oleh ruang Bowman dari glomerulus. Gromeluri terdiri atas pusat inti padat dari sel mesangial yang dikelilingi oleh kapiler. Sel parenkim dan sel endotel yang karyolisis tidak ada. Residu DDT sebesar 0,31 ppm belum memberikan dampak secara patologis pada struktur histologis dari ren. Gambar B menunjukkan kondisi ren juga dalam keadaan normal. Tubulus renalis hanya dilewati xenobiotika lipofil, tidak terionisasi; jenis xenobitika non polar akan terperfusi sangat cepat. Sifat toksik suatu toksikan sangat ditentukan oleh konsentrasi toksikan pada reseptornya (Stine \& Brown, 1996). residu DDT dengan konsentrasi 0,83 ppm (Gambar C) juga menunjukkan kondisi ren yang masih normal. Residu DDT yang tereliminasi bersama urin tidak merusak struktur mikroskopis dari ren Cerek Jawa.

\section{KESIMPULAN}

Residu DDT ditemukan pada semua organ Burung Cerek Jawa yang diteliti. Efek residu pada hepar belum menyebabkan kerusakan daerah sentrolobuler, tetapi memunculkan fibrosis, degenerasi hidrofobik, infiltrasi sel radang, dan menginduksi enzim Sitokrom P450. Pada Intestinum, residu DDT terukur tidak menyebabkan perubahan struktur histologis. Pada ren, residu DDT tertinggi tidak menyebabkan kerusakan pada komponen tubulus.

\section{DAFTAR PUSTAKA}

Guyton dan Hall. 1997. Buku Ajar Fisiologi Kedokteran. Jakarta: Penerbit Buku Kedokteran EGC.

Hayes WJ (Jr) and Laws ER (Jr). 1991. Handbook of Pesticide Toxicology. London: Academic Press, Inc. pp 743-780. Jeyaratnam J and Koh D. 2009. Buku Ajar Praktik Kedokteran Kerja. Jakarta: Penerbit buku Kedokteran EGC.

Kuehnel W. 2003. Color Atlas of Cytology, Histology and Microscopic Anatomy. Stuttgart, New York: Thieme Flexibook.

Lu FC. 2006. Toksikologi Dasar (Asas, Organ Sasaran, dan Penilaian Resiko) edisi kedua. Jakarta: Universitas Indonesia.

Made IMAG dan Niruri R. 2006. Toksikologi Umum. Bali: Jurusan Farmasi Fakultas MIPA. Universitas Udayana. 
McManus JFA and Mowry RW. 1960. Staining Methods, Histologic, and Histochemical. New York: Paul B. Hoeber, Inc. pp 58-59. Munajim F. 1990. Cara- cara Analisa Kimia. Surabaya: Balai Standarisasi dan Industri Surabaya.

Nelson WB and Gish CD. 1980. Persistance in Earthworms and Potential Hazzards to Birds of Soil Applied DDT, Dieldrin, and Heptachlor. Journal of Applied Ecology. vol 17: 295- 307.

Price and Anderson S. 1991. Patofisiologi: Konsep Klinik Proses-proses Penyakit. Jakarta: Penerbit Buku Kedokteran EGC. hal 17-23.
Ressang AA. 1984. Patologi Khusus Veteriner. Bali: NV Percetakan Bali.

Stine KE and Brown TM. 1996. Principles of Toxicology. Lewis Publishers. New York: CRC Press. Inc.

Sudaryanto A, Muchtar M, Razak $\mathrm{H}$ dan Tanabe S. 2005. Kontaminasi Organoklorin Persisten Dalam Kerang Hijau (Perna viridis) di Perairan Indonesia. Jurnal Oseanologi Limnologi Indonesia. vol 37: 1- 14

Walker CH, Hopkin SP, Sibley RM and. Peakall DB. 2001. Principles of Ecotoxicology, $2^{\text {nd }}$ edition. New York: Taylor and Francis Inc. 